\title{
Interação das tartarugas marinhas com a pesca artesanal de cerco-fixo em Cananéia, litoral sul de São Paulo
}

\author{
Natália Cristina Fidelis Bahia ${ }^{1,2 *}$ \\ Ana Cristina Vigliar Bondioli ${ }^{1,3}$ \\ ${ }^{1}$ Projeto Tartarugas, Instituto de Pesquisas Cananéia, CEP 11990-000, Cananéia - SP, Brasil \\ ${ }^{2}$ Instituto de Biociências, Universidade Estadual Paulista, Botucatu - SP, Brasil \\ ${ }^{3}$ Museu de Zoologia, Universidade de São Paulo, São Paulo - SP, Brasil \\ *Autor para correspondência \\ nath_sauva@yahoo.com.br
}

Submetido em 30/11/2009

Aceito para publicação em 26/03/2010

\section{Resumo}

As tartarugas marinhas são répteis que ocorrem ao longo de toda a costa brasileira, migrando entre as áreas de alimentação e de reprodução. O consumo de sua carne e ovos é um hábito histórico de diversas comunidades litorâneas por todo mundo. Entretanto, atualmente as principais ameaças para estes animais têm sido o aumento da pressão das artes de pesca e as alterações do meio ambiente. Neste estudo, buscou-se entender a interação entre os pescadores artesanais que utilizam o cerco-fixo como armadilha para pesca e as tartarugas marinhas que ocorrem na região de Cananéia, litoral sul de São Paulo. Através da aplicação de entrevistas, ilustrações e do acompanhamento das atividades pesqueiras, foi possível (i) verificar as percepções dos pescadores em relação a estes animais, (ii) identificar as espécies e as características morfológicas das tartarugas marinhas avistadas no local e (iii) caracterizar as capturas incidentais desses animais pelos cercos-fixos. As informações levantadas por este estudo indicam que este tipo de armadilha de pesca não influencia a sobrevivência das tartarugas marinhas. Observou-se que o local onde os cercos-fixos são montados pode influenciar na captura desses animais, sendo costões rochosos e fundos de pedras os pontos de maior ocorrência e de captura.

Unitermos: cerco-fixo, conservação, Etnobiologia, pescadores, tartarugas marinhas

\section{Abstract}

Sea turtle and artisanal cerco-fixo fishing interactions in Cananéia, south coast of São Paulo. Sea turtles are reptiles that occur on the Brazilian coast, mainly on nesting and feeding grounds. The consumption of turtle meat and eggs is an ancient habit in many coastal communities around the world. The main dangers that threaten these species are the increase in fishing and the drastic changes in the environment. This study aimed to elucidate the interaction between the artisanal fishermen and the sea turtles in Cananéia, São Paulo state, Brazil. Local fishermen had developed an artisanal trap to fish, the "cerco-fixo", and through interviews and illustrations, as well as by accompanying the fishermen' daily activities, three main aspects were verified: (i) the perception of the fishermen about the sea turtles; (ii) the identification of species and morphological characteristics of these animals; and (iii) a description of the incidental bycatch of sea turtles in these traps. The data indicates that this fishing trap is not harmful to the sea turtles. Location of traps can influence the capture of these animals, particularly those traps placed on rocky shores and other similiar points.

Key words: artisanal fish trap, conservation, Ethnobiology, fishermen, sea turtle 


\section{Introdução}

As tartarugas marinhas são animais que possuem um ciclo de vida longo e complexo, fato que dificulta estudos sobre sua biologia e ecologia. Apresentam comportamento migratório, realizando extensas viagens oceânicas durante as diferentes fases de seu desenvolvimento, tanto à procura de alimento como em busca das praias de anidação (Meylan e Meylan, 2000). A longevidade destes répteis associada às baixas taxas de crescimento populacional e maturação sexual tardia são características que tornam estas espécies mais vulneráveis à ameaça de extinção (Miller, 1997).

No Brasil, são encontradas cinco espécies de tartarugas marinhas (Caretta caretta, Chelonia mydas, Eretmochelys imbricata, Lepidochelys olivacea e Dermochelys coriacea) e todas estão catalogadas pela IUCN (União Internacional para Conservação da Natureza) como ameaçadas ou criticamente ameaçadas de extinção (IUCN, 2008).

Esses animais, historicamente, fazem parte da cultura de muitas comunidades costeiras fornecendo parte de seu sustento nutricional e econômico, por conta de sua carne e ovos. Além disso, durante muitos anos enriqueceram as crenças religiosas de muitas civilizações antigas, como a árabe e a mediterrânea (Frazier, 2003). As sociedades humanas e seus diferentes hábitos culturais causaram um grande impacto sobre as populações de tartarugas marinhas ao longo do tempo (Frazier, 2003). Entretanto, as principais ameaças atuais à sobrevivência destes animais são o aumento da pressão das artes de pesca e as alterações do meio ambiente (Wetherall et al., 1993).

Entender a interação dos pescadores com estes animais levando-se em conta o tipo de aparelho de pesca utilizado, seu funcionamento, localização e a utilização de iscas são elementos fundamentais para melhor compreender as capturas incidentais e hábitos de cada espécie de tartaruga (Pupo et al., 2006). No Brasil, a pesca artesanal ainda é pouco estudada e existem restritas estatísticas sobre tal atividade (Silvano, 2004), e estudos sobre a captura incidental e a interação de tartarugas marinhas com a comunidade pesqueira artesanal são ainda mais raros (Pupo et al., 2006).
Dependentes de recursos aquáticos nas suas atividades de pesca e extrativismo, as comunidades litorâneas passaram a explorar ambientes marinhos, estuarinos e dulcícolas de forma própria, adquirindo conhecimento detalhado sobre práticas e crenças tanto a respeito da interação dos seres vivos entre si como com o ambiente (Berkes et al., 2006). Este é caracterizado por ser tanto cumulativo quanto dinâmico, construído a partir de diversos conjuntos de práticas, rituais e arranjos institucionais que promovem a capacidade de monitorar mudanças, rever e ajustar (adaptar) as práticas segundo o reconhecimento de suas deficiências ou falhas (Berkes et al., 2000).

Este cenário possibilita, além de um conhecimento refinado do ambiente em que vivem, uma potencial parceria nos estudos para a conservação de recursos biológicos (Diegues e Arruda, 2001; Maldonado, 2002; Hanazaki, 2003), incluindo as tartarugas marinhas. Além disso, o diálogo entre o conhecimento ecológico tradicional e o conhecimento científico (em uma abordagem participativa) torna-se também uma ferramenta extremamente valiosa na tomada de decisões envolvendo a comunidade local, principalmente no que se refere às questões ambientais (Marques, 2002).

Dentro deste contexto, o presente estudo teve por objetivo relatar a interação entre os pescadores artesanais que utilizam cercos-fixos como arte de pesca e as tartarugas marinhas encontradas na região de Cananéia e descrever a comunidade de pescadores locais discriminando e relacionando alguns costumes e práticas pesqueiras com os hábitos desses animais e as capturas incidentais.

\section{Material e Métodos}

\section{Área de estudo}

A região de Cananéia, localizada no sistema estuarino-lagunar de Cananéia-Iguape-Ilha Comprida no extremo sul da costa paulista $\left(25^{\circ} \mathrm{S}-48^{\circ} \mathrm{W}\right)$, caracteriza-se por apresentar um extenso canal marinho, que se situa entre a Ilha de Cananéia e a Ilha Comprida e também, pela Baía Trapandé que separa as ilhas acima citadas da Ilha do Cardoso (Figura 1) (Mendonça, 1998). 


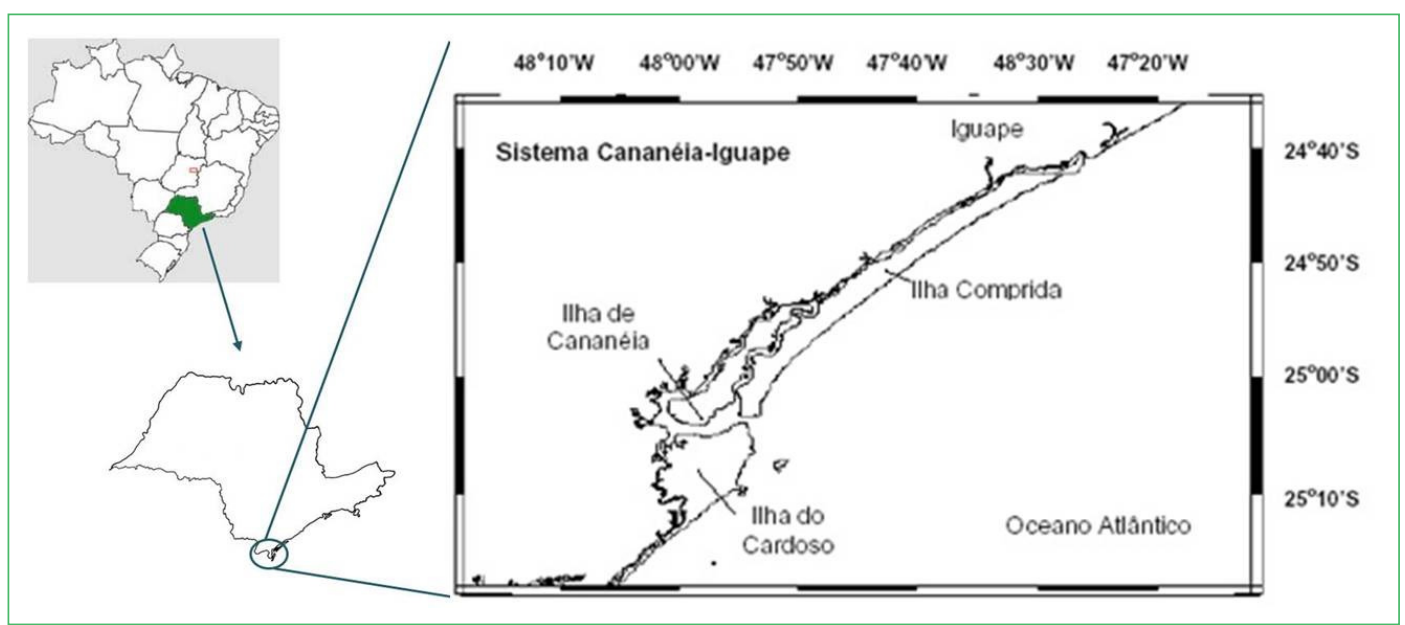

FIGURA 1: Parte da região de Cananéia situada no sistema estuarino-lagunar de Cananéia-Iguape-Ilha Comprida (Fonte: modificado do Google e Cunha-Lignon, 2001).

Diferentes ecossistemas, como a mata de restinga, a Mata Atlântica, as praias, os costões rochosos e o ambiente marinho, nos quais se observa grande riqueza de espécies animais, compõe este complexo estuarino (Occhpinti, 1963). Essa riqueza de recursos disponíveis proporciona uma importante atividade econômica para a região, principalmente para comunidade local de pescadores artesanais (Mendonça e Katsuragawa, 2001).

O cerco-fixo (Figura 2) foi implantado na primeira metade do século XX em Cananéia e hoje é a principal arte de pesca utilizada no estuário (Mendonça e Katsuragawa, 2001). Este se caracteriza por ser uma armadilha fixa, um tipo de "curral", construída dentro do estuário e disposta perpendicularmente à margem dos manguezais (Mendonça e Katsuragawa, 2001). A estrutura básica do cerco-fixo é montada através de moirões (principalmente pertencentes às famílias Myrtaceae, Melastomataceae, Lauraceae, Annonaceae, Sapotaceae, Rubiaceae e Fabaceae). Após a disposição destes, colocam-se as chamadas "panadas" ou "panos", que são bambus ou taquaras-mirim (Merostachys sp. e Chusquea sp.), confeccionadas e tecidas (amarradas umas as outras) com arame (Oliveira, 2007; Hanazaki et al., 2009), sendo que a distância entre eles varia de

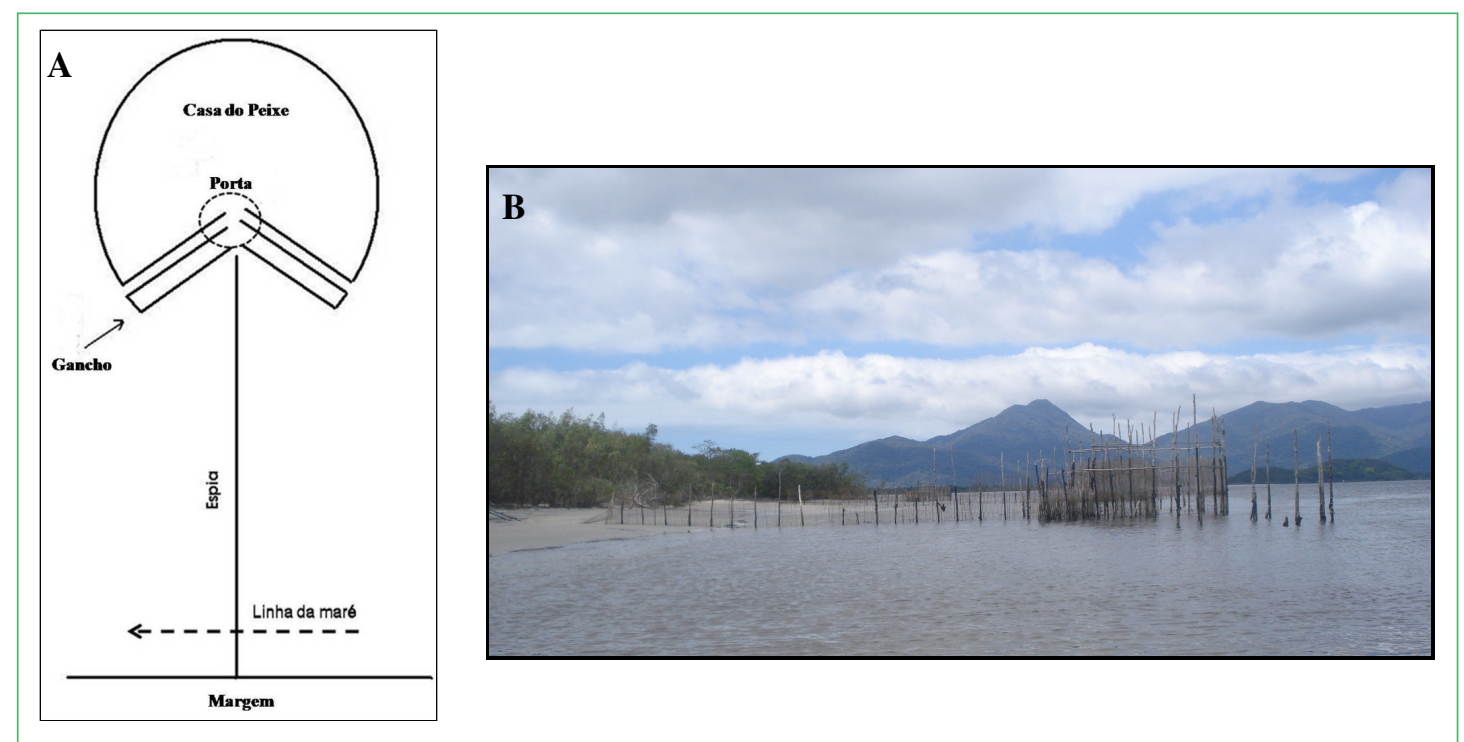

FIGURA 2: a) Desenho esquemático de um cerco-fixo; b) Cerco-fixo localizado na região da Ponta da Trincheira (Ilha Comprida) (Foto: Projeto Tartarugas / IPeC). 
acordo com a espécie alvo e época do ano (Mendonça e Katsuragawa, 2001). Para aumentar a durabilidade da armadilha e o reaproveitamento das taquaras e moirões, estas podem ser envolvidas por plásticos (plastificação) (Oliveira, 2007).

\section{Coleta e análise de dados}

Este estudo foi realizado entre maio de 2007 e dezembro de 2008, em duas etapas. Na etapa inicial (maio a agosto de 2007), foram realizados os primeiros contatos com a comunidade e o acompanhamento das atividades relacionadas aos cercos-fixos (principalmente a coleta de dados biométricos das tartarugas marinhas capturadas incidentalmente), a fim de construir uma parceria de trabalho e obter as informações necessárias para elaboração de uma entrevista semi-estruturada (Viertler, 2002). Neste tipo de entrevista, alguns tópicos são fixos e outros são definidos conforme o andamento desta, visando a liberdade do pesquisador em aprofundar-se em determinadas questões durante a condução da entrevista (Viertler, 2002). Esta foi testada com três pescadores de idades variadas (dois donos de cercos-fixos e um familiar que auxilia na pesca), cada um deles corresponde a uma armadilha diferente localizadas em Cananéia, Ilha Comprida e Ilha do Cardoso, respectivamente.

O acompanhamento das atividades pesqueiras consistiu principalmente na presença dos pesquisadores (previamente avisados pelos cerqueiros responsáveis) durante a visita e/ ou a retirada dos peixes e outros animais da armadilha (conhecida como "despesca"), como observação da confecção e montagem dos cercos-fixos.

A segunda etapa correspondeu à coleta de dados etnobiológicos e socioeconômicos, além da continuação da tomada das medidas biométricas dos quelônios capturados. Foram então realizadas as entrevistas semiestruturadas, juntamente com conversas informais e observações diretas (Viertler, 2002). O critério utilizado na escolha do entrevistado não foi aleatório, procurou-se trabalhar com proprietários dos cercos e seus familiares, dependendo da disposição para participar da pesquisa. Os pescadores que utilizam o cerco-fixo na pesca são conhecidos como "cerqueiros". Alguns dos entrevistados foram localizados na primeira etapa do estudo, e outros foram indicados pelos primeiros a medida que o estudo era realizado.

A análise dos resultados obtidos é essencialmente descritiva. Cálculos de estatística descritiva foram utilizados a fim de caracterizar as comunidades estudadas e auxiliar na descrição das atividades pesqueiras (Bernard, 1995).

\section{Resultados e Discussão}

\section{Caracterização sócio-econômica}

Foram realizadas 29 entrevistas durante o período de estudo. A maioria dos cerqueiros entrevistados é do sexo masculino (90\%), havendo somente três $(10 \%)$ mulheres. Destas, apenas uma pesca sozinha, e as demais são acompanhantes e auxiliares de seus respectivos maridos. Dentre os pescadores, $58 \%$ começaram a trabalhar com a pesca desde cedo, com idades entre sete e 14 anos. Durante a realização do presente estudo, suas idades variaram de 18 a 71 anos, com uma média de 44,5 anos. As percentagens de pescadores entre as faixas etárias de 18 a 30 anos, 31 a 40 anos, 41 a 50 anos, 51 a 60 anos e de 60 anos pra cima foram, respectivamente, $20 \%, 20 \%, 17 \%, 28 \%$ e $15 \%$.

Grande parte dos cerqueiros é proveniente da própria região: $75 \%$ destes nasceram em Cananéia (incluindo a Ilha do Cardoso), 6\% na Ilha Comprida e os $19 \%$ restantes em outras localidades (Iguape, PariqueraAçu, Guaraqueçaba, e interior do Paraná). Atualmente, $51 \%$ dos pescadores entrevistados residem em Cananéia, $41 \%$ na Ilha do Cardoso e apenas $8 \%$ em Ilha Comprida.

Os pescadores podem construir os cercos-fixos próximos a suas residências ou também distantes delas. As porcentagens de armadilhas construídas na Ilha da Casca (Ilha do Cardoso), Núcleo Marujá (Ilha do Cardoso), Núcleo Perequê (Ilha do Cardoso), Ilha Comprida (Boqueirão Sul) e Cananéia (localidades destacadas na Figura 3), foram, respectivamente, 4\%, $12 \%, 48 \%, 24 \%$ e $12 \%$. Alguns entrevistados montam mais de um cerco, podendo ser um ao lado do outro como em localidades diferentes, visto que o número total de armadilhas $(n=33)$ é maior que o de entrevistados. Dos 
entrevistados, $62 \%$ afirmaram que montam os cercosfixos com sócios que são seus familiares; $21 \%$ com outros sócios; e os outros $17 \%$ dos cerqueiros montam os cercos-fixos sozinhos. A sociedade é composta por dois ou mais pescadores que dividem por igual tanto os lucros como as despesas e possíveis prejuízos.

Percebe-se, entre os entrevistados, que há preferência de que seus filhos optem por outras formas de trabalho, pois a opinião de que a pesca piorou bastante nestes últimos anos foi unânime. Reflexos dessa situação puderam ser observados em relação à forma de obtenção da renda familiar, na qual $16 \%$ dos pescadores dependem exclusivamente da renda da pesca para seu sustento e de sua família e, outros $42 \%$ adotam a pesca como principal atividade econômica, porém possuem fontes alternativas de renda. $\mathrm{O}$ restante $(42 \%)$ não depende da atividade pesqueira como principal fonte de renda, pescam somente para consumo próprio ou para complementar a renda familiar.

Além disso, foi possível observar também que 38\% dos pescadores diminuem o esforço de pesca na época de verão e assumem atividades voltadas para o turismo na região. Tal situação de enfraquecimento da pesca artesanal devido ao surgimento de outras possibilidades de trabalho mais rentáveis, principalmente atividades econômicas ligadas ao turismo local, é igualmente relatada por Cardoso (2004) em seu trabalho realizado na Ilha do Cardoso e por Diegues (2004) em outras localidades do litoral do estado de São Paulo.

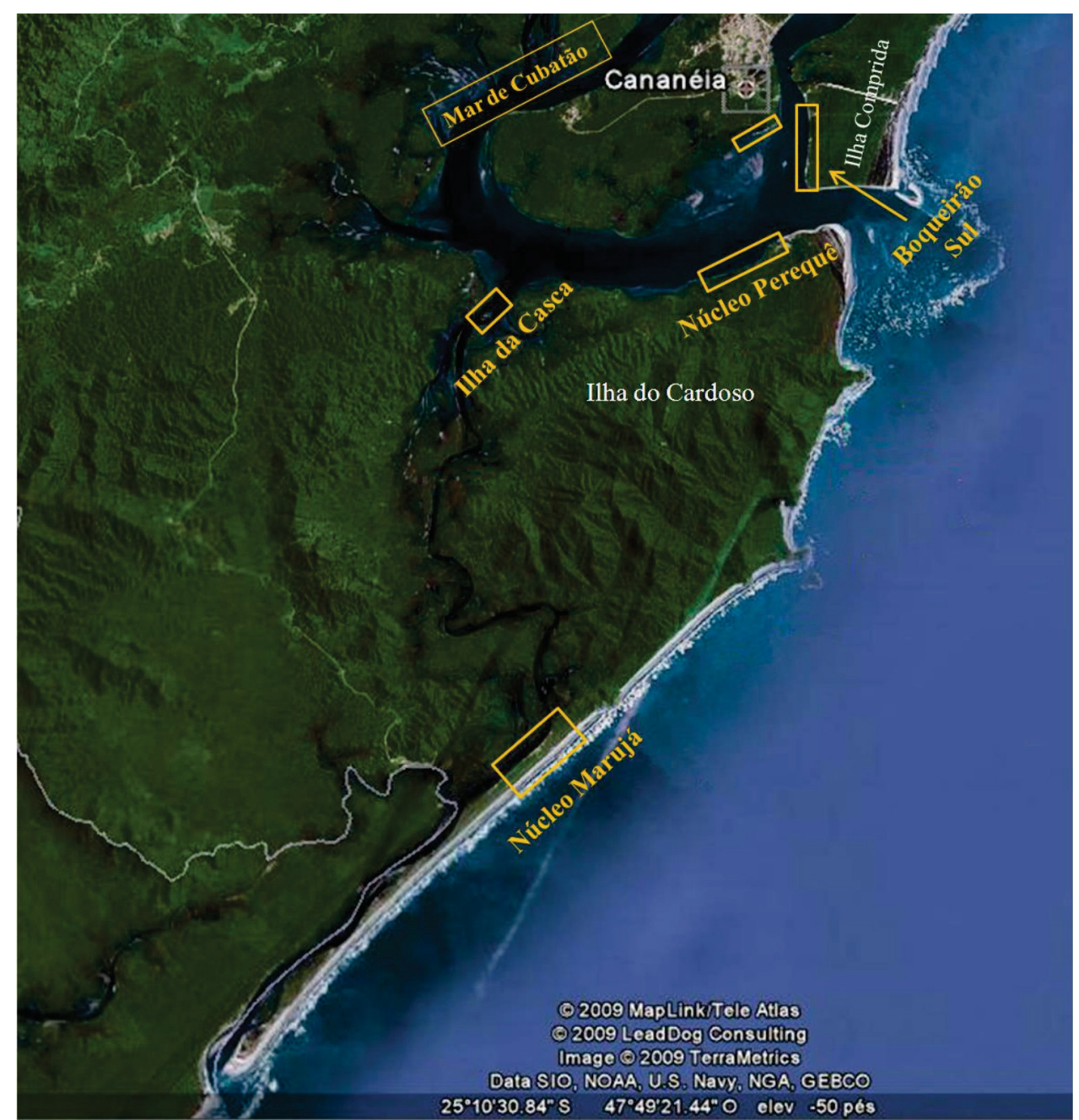

FIGURA 3: Localização das áreas onde os entrevistados construíram os cercos-fixos: Ilha da Casca Núcleo Marujá, Núcleo Perequê, Boqueirão Sul e Cananéia (Fonte: modificado do Google Earth). 


\section{As tartarugas marinhas}

Alguns pescadores (31\% dos entrevistados) têm conhecimento sobre a classificação biológica básica destes animais, ou seja, que estes pertencem ao grupo dos répteis. Entretanto, percebe-se que outros 69\% classificam de forma peculiar os animais com os quais interagem durante a atividade pesqueira dependendo de suas experiências pessoais. Um exemplo disso é a seguinte descrição dada por um dos entrevistados:

"A tartaruga é um peixe, pois ela entra no cerco e não consegue sair como os peixes. Ela fica presa como os peixes por causa da maré. Diferente da lontra (que não é um peixe) que sabe entrar e sair do cerco." (S. T., 61 anos, cerqueiro)

A percepção dos pescadores quanto às espécies de tartarugas avistadas na região foi registrada, apresentando resultados interessantes. Para $51 \%$ dos entrevistados, ocorre apenas um "tipo" de tartaruga marinha na região, 20\% destes acreditam ser de dois "tipos" diferentes e $29 \%$ disseram ser de mais de dois "tipos". A Figura 4 apresenta as diferentes percepções dos pescadores sobre os "tipos" desses animais que aparecem na região de Cananéia.
A maioria dos entrevistados (55\%) relata que a tartaruga mais comum na região é a tartaruga verde. Ao serem indagados a respeito do nome popular desses animais, comentam que costumam se referir apenas como "tartaruga", sem diferenciá-las por "tipo". Corroborando com esta percepção, é possível verificar na Tabela 1, que tartarugas marinhas da espécie Chelonia mydas apresentaram maior ocorrência na região de Cananéia do que as outras quatro espécies. Esses dados foram registrados pelo Projeto Tartarugas (pertencente ao Instituto de Pesquisas Cananéia - IPeC $)^{1}$ no período de outubro de 2003 a dezembro de 2008.

Um assunto bastante polêmico abordado é a utilização das tartarugas como recurso alimentar. A maioria dos entrevistados (56\%) disse que antigamente era muito comum o uso desses animais para esse fim; contudo, atualmente poucos se alimentam de tartarugas. Um dos entrevistados fez o seguinte relato:

"Aqui em Cananéia quase não tem mais gente que come carne de tartaruga, antigamente, tinha bastante. Ainda hoje quando bate tartaruga morta na rede (rede de emalhe), o pessoal aproveita e come". (I. N., 48 anos, cerqueiro)

\begin{tabular}{|c|c|c|}
\hline "Tipo" & Características dadas pelos pescadores & Justificativas \\
\hline Um & $\begin{array}{l}\text { Quanto à carapaça: "casco arredondado e } \\
\text { dradriculado" } \\
\text { Quanto à coloração: "o casco é escuro, } \\
\text { brilhante e rajado”; "o casco é marrom"; } \\
\text { o casco varia de mais preto, outros mais } \\
\text { amarelados e outros mais esverdeados"; } \\
\text { "tem casco mais claro e casco mais } \\
\text { escuro". }\end{array}$ & $\begin{array}{l}\text { Os pescadores relacionam essas variações } \\
\text { pela diferença de idade entre os animais, } \\
\text { sendo que as tartarugas marinhas mais } \\
\text { novas possuem as carapaças mais claras } \\
\text { e mais uniformes e as mais velhas } \\
\text { apresentam as carapaças mais escuras, } \\
\text { menos uniformes e com maior incidência } \\
\text { de epibiontes. }\end{array}$ \\
\hline Mais de um & $\begin{array}{l}\text { Quanto à carapaça: "cascos mais ovais } \\
\text { (referindo-se a tartaruga verde) e outros } \\
\text { mais redondos (referindo-se a tartaruga } \\
\text { cabeçuda)"; "casco triangular (referindo-se } \\
\text { à tartaruga de pente) e casco reto (referindo- } \\
\text { se às tartarugas verde e cabeçuda)". }\end{array}$ & $\begin{array}{l}\text { Os pescadores justificam essas variações } \\
\text { por serem animais pertencentes a diferentes } \\
\text { tipos: tartarugas verde, cabeçuda e de pente } \\
\text { (mais comuns na região). }\end{array}$ \\
\hline
\end{tabular}

FIGURA 4: Descrição das diferentes percepções dos pescadores sobre os "tipos" de tartarugas marinhas que aparecem na região de Cananéia (Fonte: Dados da pesquisa). 
Dentre os cerqueiros entrevistados, $62 \%$ disseram que alguma vez já comeram esses animais e os $38 \%$ restantes negaram. Essa situação descrita pode representar uma mudança de hábito alimentar dos pescadores; entretanto, é necessário levar em consideração o receio em tratar deste tema, em face da problemática da legislação ambiental para a proteção desses animais.

TABELA 1: Ocorrência de tartarugas marinhas (tanto vivas como mortas) registradas pelo Projeto Tartarugas (Instituto de Pesquisas Cananéia) na região de Cananéia (período: outubro de 2003 a dezembro de 2008) em porcentagem.

\begin{tabular}{lc}
\hline \multicolumn{1}{c}{ Espécie } & $\begin{array}{c}\text { Porcentagem de ocorrência } \\
(\mathbf{\%})\end{array}$ \\
\hline Chelonia mydas & 92,85 \\
Caretta caretta & 4,91 \\
Eretmochelys imbricata & 0,66 \\
Lepidochelys olivacea & 0,22 \\
Dermochelys coriácea & 0,22 \\
Não identificada & 1,14 \\
& $100(\mathrm{~N}=448)$ \\
\hline
\end{tabular}

Fonte: Dados do Projeto Tartarugas - IPeC.

Os pescadores estudados por Pupo et al. (2006) apresentaram um comportamento diferente, os pesquisadores observaram que mais de $60 \%$ de seus entrevistados ainda consomem a carne de tartaruga, relatando utilizar estes animais apenas quando aparecem mortos na rede de emalhe (88\%). No presente estudo, acredita-se na diminuição do consumo desses animais por pescadores que utilizam cercofixo, pois estes não apresentam risco à sobrevivência das tartarugas marinhas capturadas.
Tanto na presente pesquisa como no trabalho de Pupo et al. (2006), observou-se que os pescadores têm consciência da proibição da comercialização e da utilização das tartarugas marinhas, o que provavelmente também acarreta a diminuição atual deste uso em relação ao passado. Entretanto, em muitos casos, pode-se constatar que o conhecimento da legislação nem sempre estava acompanhado da compreensão sobre o motivo de tal proibição. Em $72 \%$ das entrevistas, os pescadores não demonstraram conhecer o status atual de ameaça que estes animais sofrem, motivo pelo qual foi criada uma lei específica para estes animais, proibindo sua captura e utilização no Brasil desde 1986 (Portaria da SUDEPE, $n^{\circ} 005$ de 31 de janeiro de 1986, IBAMA 2009).

\section{As tartarugas marinhas e os cercos- -fixos}

Todos os pescadores entrevistados relatam casos de tartarugas marinhas que entraram em seus cercos-fixos (Figura 5). Segundo a maioria dos entrevistados (55\%), os cercos-fixos localizados próximos a Ilha do Cardoso (Núcleo Perequê) e ao rio Taquari (desemboca no Mar de Cubatão) capturam incidentalmente uma quantidade maior de tartarugas marinhas do que os outros (Cananéia e Ilha Comprida) (Figura 3). Com o auxílio de imagens, obteve-se que a espécie de tartaruga, apontada com unanimidade, como mais frequentemente capturada por estas armadilhas é a tartaruga verde, sendo que $31 \%$ dos entrevistados relataram também capturas de tartaruga cabeçuda e $21 \%$ de tartaruga de pente.

Na Tabela 2, é possível observar dados relacionando as espécies de tartarugas marinhas capturadas

TABELA 2: Despescas acompanhadas pelas pesquisa-doras do Projeto Tartarugas (Instituto de Pesquisas Cananéia) no período de janeiro de 2007 a dezembro de 2008.

\begin{tabular}{|c|c|c|c|}
\hline & \multicolumn{3}{|c|}{ Localidades } \\
\hline & Cananéia & Ilha Comprida & Ilha do Cardoso (Núcleo Perequê) \\
\hline Despescas acompanhadas (\%) & 2 & 24 & 42 \\
\hline Espécies de tartarugas marinhas capturadas & Chelonia mydas & $\begin{array}{l}\text { Chelonia mydas } \\
\text { Eretmochelys imbricata }\end{array}$ & $\begin{array}{l}\text { Chelonia mydas } \\
\text { Eretmochelys imbricata }\end{array}$ \\
\hline Total de Capturas (\%) & 2 & $\begin{array}{l}\text { C. mydas }-32 \\
\text { E. imbricata }-1\end{array}$ & $\begin{array}{l}\text { C. mydas }-116 \\
\text { E. imbricata }-1\end{array}$ \\
\hline Frequência de tartaruga por despesca & 1,00 & 1,38 & 2,78 \\
\hline $\begin{array}{l}\text { Comprimento médio da carapaça }(\mathrm{cm}) \text { das tartaru- } \\
\text { gas marinhas capturadas }\end{array}$ & $\begin{array}{l}34,75( \pm 1,06) \\
(34,00-35,50)\end{array}$ & $\begin{array}{l}38,25( \pm 3,27) \\
(31,00-44,00)\end{array}$ & $\begin{array}{l}37,00( \pm 5,52) \\
(32,00-63,0)\end{array}$ \\
\hline
\end{tabular}

Fonte: Dados da pesquisa e do Projeto Tartarugas - IPeC. 
incidentalmente em relação à localização das armadilhas de pesca, a quantidade, os respectivos comprimentos médios e desvios padrões, a menor e a maior medida registrada, obtidos através do acompanhamento de algumas das despescas realizadas na região pelos integrantes do Projeto Tartarugas (IPeC). Esses dados corroboram a situação anteriormente relatada pelos pescadores, a grande quantidade de capturas incidentais nos cercos-fixos localizados na Ilha do Cardoso (Núcleo Perequê).

Devido à falta de trabalhos sobre essa temática na região estudada, os dados da Tabela 2 são as únicas informações a serem comparadas com os dados etnobiológicos obtidos pelo presente estudo. É necessário ressaltar que o monitoramento das praias e o acompanhamento das atividades pesqueiras não foram realizados de forma contínua, dependendo da disponibilidade dos pesquisadores, das condições climáticas e da colaboração dos pescadores.

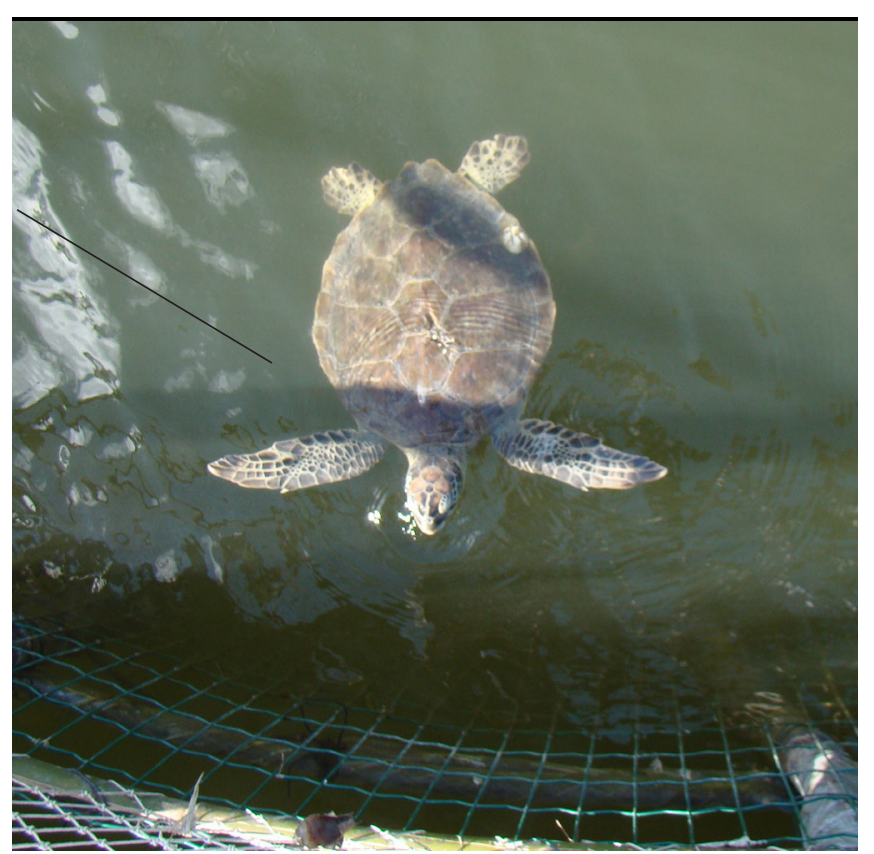

FIGURA 5: Tartaruga verde (Chelonia mydas) capturada por um cerco-fixo localizado na Ilha do Cardoso. (Foto: Daniela Godoy).
Em relação ao tamanho dos animais capturados, a maioria dos pescadores acredita não haver relação entre o tamanho e a entrada dos quelônios nas armadilhas, como mostra o seguinte relato:

"Você sabe como uma tartaruga desse tamanho entra no cerco? (indicando com as mãos um comprimento aproximado entre 40 a $50 \mathrm{~cm}$ ) Ela entra de ladinho pela porta, a porta é apertada [a porta, localizada na casa do peixe, é a principal estrutura do cerco-fixo, e a sua disposição em "V" tem o mesmo funcionamento de um gargalo, sendo esta maleável na entrada e permitindo que os peixes, forçando sua abertura, consigam entrar na casa do peixe, entretanto não consigam forçar a saída]. A raia faz isso também". (A. C., 57 anos, cerqueiro)

Outros afirmam que a porta do cerco costuma ceder bastante ("laceia") por ser feita de taquara. Com o auxílio de uma fita métrica, os entrevistados apontaram que as tartarugas marinhas capturadas por essas armadilhas estão dentro de um intervalo de 30 a $70 \mathrm{~cm}$ de comprimento de carapaça, sendo a faixa entre 40 e $50 \mathrm{~cm}$ a mais comum (mencionada por $45 \%$ dos entrevistados). Esses dados, comparados com as informações da Tabela 2, demonstram semelhança aos dados biométricos dos animais capturados obtidos pelos pesquisadores ao acompanharem as despescas.

\section{Captura incidental}

Para a maioria dos pescadores, as tartarugas marinhas, assim como os peixes, nadam a favor da maré, encontram a espia do cerco-fixo (que funciona como uma barreira), entram na armadilha, e não conseguem sair dela, ficando presas (relatado por $97 \%$ dos entrevistados).

Dentre os cerqueiros, $24 \%$ dos entrevistados acreditam que esses animais se aproximam do cercofixo para se alimentar das algas incrustadas nas taquaras mais antigas. Estes pescadores relataram ainda que em armadilhas mais novas, as tartarugas marinhas não são capturadas ou são capturadas em menor frequência do que nos cercos-fixos mais antigos, devido ao maior acúmulo de algas fixadas em suas taquaras. Um exemplo é o relato a seguir: 
"Os cercos de taquara em dois meses criam algas, ela vai comendo em volta do cerco as algas e quando vê caiu dentro do cerco". (S. T., 61 anos, cerqueiro)

Alguns entrevistados (10\%) afirmam ainda que os quelônios margeiam os cercos-fixos para se alimentar dos cardumes de peixes de pequeno porte, e outros $10 \%$ acreditam que este fato deve-se tanto pelos animais acompanharem os cardumes de peixes pequenos como por procurar as algas fixadas nas taquaras. Tais afirmações coincidem com as observações feitas por $41 \%$ dos entrevistados, os quais durante suas atividades pesqueiras já presenciaram as tartarugas marinhas capturadas pelos cercos-fixos se alimentando de pequenos peixes, águas vivas e caravelas encontradas dentro da armadilha, bem como de algas incrustadas nas taquaras.

Outra questão relevante levantada durante o estudo é se as tartarugas marinhas prejudicam a pesca. Para a maioria dos pescadores $(90 \%)$ este fato não é verídico, pois não se alimentam de peixes de alto valor comercial bem como não estragam as armadilhas. Entretanto, relatam que elas podem atrapalhar o momento da despesca por dificultar a retirada do peixe e há o risco de quebrarem as taquaras que compõem a armadilha, em razão de seu peso e da quantidade capturada.

Apenas três pescadores $(10 \%)$ acreditam que estes animais prejudicam as atividades pesqueiras; dois destes afirmaram que, quando elas são capturadas, permanecem na porta da armadilha, interrompendo a entrada dos outros peixes. Houve relatos de que as tartarugas marinhas podem afugentar os peixes ("como a tainha e a pescada") que não entram na armadilha, e podem estragar o cerco-fixo e a rede de despesca ("ela morde e arrebenta a rede com a serrinha que ela tem na boca", se referindo à ranfoteca serrilhada característica da tartaruga verde).

Em relação às condições dos animais capturados, para a maioria dos entrevistados $(83 \%)$ as tartarugas marinhas não se ferem quando presas no cercofixo. Entretanto, os 17\% dos entrevistados restantes mencionam que elas podem se machucar quando as armadilhas são feitas de tela ou quando os moirões e as taquaras não estão plastificados. Todos os pescadores disseram que as tartarugas marinhas não machucam os peixes capturados junto com elas. Contudo, para 17\% dos entrevistados, elas podem assustá-los. Um exemplo é o relato a seguir:

"Talvez ela assuste os peixes, por exemplo, o robalo, que é nervoso. Pode ser perigoso, no susto ele pode furar o cerco ou pela taquara escapar sem se machucar ou se o cerco for de tela de ferro, ele fica preso e morre". (S. N., 58 anos, cerqueiro)

Relatos como estes são importantes na conservação das tartarugas marinhas. Se estes animais danificassem as armadilhas e/ ou o pescado capturado, desenvolveriam uma aversão por parte dos pescadores, como pode ser registrado para as lontras presentes na região deste estudo.

\section{Variações ambientais influenciando nas capturas de tartarugas}

A Tabela 3 apresenta o relato dos entrevistados sobre a ocorrência de capturas das tartarugas marinhas em relação à época do ano e ao local onde são construídos os cercos-fixos. Dentre os entrevistados que afirmaram não saber a época em que as tartarugas são mais capturadas, um deles relata que: "ela cai mais no cerco quando é maré de lua (maré sizígia)". Para os pescadores que relataram maior captura desses quelônios durante o verão, a argumentação utilizada foi que essa época apresenta maior frequência de cardumes de peixes pequenos (por exemplo, "cardumes de paratizinhos que elas gostam de comer") e pela maior incidência de algas fixadas nas armadilhas.

TABELA 3: Ocorrência de capturas incidentais das tartarugas marinhas em relação à época do ano e o local onde os cercos-fixos são construídos na visão dos entrevistados.

\begin{tabular}{l|c|c|c|c}
\hline \multicolumn{2}{|c|}{} & \multicolumn{4}{c}{ Localidades } \\
\hline $\begin{array}{c}\text { Época do } \\
\text { ano }\end{array}$ & Frequência & Cananéia & $\begin{array}{c}\text { Ilha do } \\
\text { Cardoso }\end{array}$ & $\begin{array}{c}\text { Ilha } \\
\text { Comprida }\end{array}$ \\
\hline Verão & 13 & 5 & 4 & 4 \\
Inverno & 13 & - & 10 & 3 \\
Não sabe & 3 & 3 & - & - \\
\hline
\end{tabular}

Os cerqueiros que apontaram maior incidência de capturas no inverno (correspondente aos meses de maio a agosto) evidenciaram que nesse período a água 
torna-se mais escura e o tempo mais claro, dificultando a percepção da armadilha por estes animais. Além disso, alguns pescadores afirmaram que a água (dentro do canal) tem salinidade maior durante essa época do ano; assim, as tartarugas se deslocam do mar aberto para dentro do canal, principalmente quando as condições em alto mar estão ruins.

Durante a realização do presente estudo, os pesquisadores do Projeto Tartarugas (IPeC) registraram 150 tartarugas marinhas presas por cercos-fixos localizados tanto na Ilha do Cardoso como na Ilha Comprida, sendo que $53 \%$ das capturadas ocorreram durante o inverno (período de abril a setembro). Situação oposta ao que foi verificada por Frazier (1984) e Pupo et al. (2006) na costa uruguaia e catarinense, respectivamente. Vale ressaltar para o presente estudo que o número de cercos-fixos montados e o esforço de pesca são maiores no inverno devido à pesca da tainha (Mendonça e Katsuragawa, 2001), fato este que poderia interferir na percepção dos pescadores e na captura incidental desses animais, e consequentemente, nos dados obtidos no presente trabalho.

Por fim, verificou-se a ocorrência de capturas de tartarugas em relação à pluviosidade da região, sendo que para a maioria dos entrevistados (69\%) não existe uma relação direta entre as capturas incidentais e a quantidade de chuva, enquanto que $21 \%$ dos pescadores relatam que na época de menor incidência de chuva, a captura desses animais pelos cercos-fixos é maior. Para os $10 \%$ restantes, a captura de tartarugas marinhas pelos cercos-fixos é maior na época de maior incidência de chuva (correspondente aos meses de junho a agosto).

Através deste estudo foi possível concluir que o cerco-fixo não causa risco de vida às tartarugas marinhas capturadas, pois estas permanecem vivas até o momento da despesca. Este fato provavelmente desestimula o consumo desses animais, diferente de petrechos como a rede de emalhe, na qual estas geralmente são recolhidas afogadas ou mortas. Além disso, peixes de pequeno porte são muitas vezes liberados pelos pescadores durante a despesca.

O local onde o cerco-fixo é montado, a dinâmica da maré e a presença de alimentos são fatores que podem interferir na captura incidental das tartarugas marinhas.
Observou-se que armadilhas localizadas próximos aos costões rochosos e fundos de pedras possuem uma maior incidência de capturas incidentais de tartarugas marinhas, provavelmente relacionadas aos hábitos alimentares e locais de refúgio destes animais. Estudos sobre os fatores bióticos (comportamento, tamanho dos animais capturados na região) e abióticos (dinâmica do vento e chuva, salinidade, estação do ano) que possam alterar o comportamento das tartarugas marinhas e, por consequência, a sua capturabilidade por essas armadilhas de pesca, são necessários para compreender melhor como e porque tais capturas ocorrem. Conforme observado neste trabalho, a literatura sobre os quelônios e sua interação com as práticas pesqueiras artesanais é ainda pouco publicada e o presente trabalho contribuiu para a ampliação do conhecimento a respeito deste tema, descrevendo algumas práticas pesqueiras e registrando o conhecimento de pescadores da região de Cananéia sobre as tartarugas marinhas.

Cabe destacar a importância do conhecimento dos pescadores sobre o assunto, gerado a partir da íntima relação entre a atividade de pesca artesanal e o meio ambiente. Estes podem não reconhecer a separação em espécies biológicas destes animais, entretanto, suas experiências trazem conhecimentos práticos e/ ou observações que a ciência conservadora não conseguiria registrar. O resgate desta sabedoria pode auxiliar na busca pela diminuição da captura incidental das tartarugas através de outras artes de pesca letais para estes animais, por meio da conscientização dos pescadores e na tentativa de formular medidas mitigadoras deste risco, mediante pesquisas específicas sobre este tema. Além disso, o reconhecimento deste conhecimento local mostra-se importante no diálogo com o estudo científico para a conservação e seus habitats.

Este intercâmbio de informações entre o universo científico e a cultura local é um passo importante para a criação de planos de manejos adequados à realidade da comunidade, bem como a possibilidade de estabelecer parcerias para a conservação dos recursos naturais, os quais muitas vezes têm grande importância na vida cotidiana destas comunidades. Além disso, esta abordagem abre perspectivas que podem gerar contribuições expressivas para melhorias sócio- 
ambientais bem como na instigação de novos temas.

\section{Agradecimentos}

Aos pescadores de Cananéia e Ilha Comprida pela ajuda na realização deste projeto, principalmente as famílias Neves, Cardoso e do Seu Zé Carlos por abrirem muitas portas e acreditarem na importância do trabalho. À equipe de pesquisadores do Instituto de Pesquisas Cananéia (IPeC), principalmente as biólogas Bárbara Loreto de Oliveira, Daniela Godoy, Letícia Quito, Ana Carolina Luchetta e Daiana Bezerra pelo apoio no trabalho de campo.

\section{Referências}

Bernard, H. R. 1995. Analisys of quantitative data. In: Bernard, H. R. (Ed.). Research methods in anthropology - Qualitative and quantitative approaches. Altamira Press, Lanham, USA, p.360392.

Berkes, F.; Mahon, R.; Mcconney, P.; Pollnac, R.; Pomeroy, R. 2006. Gestão da pesca de pequena escala - Diretrizes e métodos alternativos. FURG Editora, Rio Grande, Brasil, 360pp.

Cardoso, T. A. 2004. Subsídios para o manejo participativo da pesca artesanal da manjuba no Parque Estadual da Ilha do Cardoso, SP. Dissertação de Mestrado, Universidade Federal de São Carlos, Brasil, 101pp.

Diegues, A. C. 2004. A mudança como modelo cultural: O caso da cultura caiçara e a urbanização. In: Diegues, A. C. (Org.). Enciclopédia caiçara: $O$ olhar do pesquisador. Editora HUCITEC, São Paulo, Brasil, p.21-48.

Diegues, A. C.; Arruda, R. S. V. 2001. Saberes tradicionais e biodiversidade no Brasil. USP/NUPAUB/MMA, São Paulo, Brasil, 176pp.

Frazier, J. 1984. Las tortugas marinas en el Oceano Atlântico Sur Occidental. Associacion Herpetologica Argentina, 2: 2-21.

Frazier, J. 2003. Prehistoric and ancient historic interactions between humans and marine turtles. In: Lutz, P. J. \& Musick, J. A. (Eds.). The biology of sea turtles. CRC Press, New York, USA, p.6-38.

Hanazaki, N. 2003. Comunidades, conservação e manejo: O papel do conhecimento ecológico local. Biotemas, 16 (1): 23-47.

Hanazaki, N.; Oliveira, F. C. de; Miranda, Tatiana Mota; Peroni, N. 2009. Ethnobotany of artisanal fishers. In: Lopes, P. \& Begossi, A. (Orgs.). Current Trends in Human Ecology. Cambridge Scholars Publishing, Newcastle, UK, p.101-124.

IBAMA - Instituto Brasileiro do Meio Ambiente e dos Recursos Naturais Renováveis. 2009. Portaria da Sudepe, n. 005/1986. Disponível em <http://www.mp.sp.gov.br/.../Portaria\%20N-0051986\%20Pesca.htm>. Acesso em 10 de outubro de 2009.
IUCN - International Union for Conservation of Nature and Natural Resources. 2008. IUCN Red list of threatened species. Disponível em $<$ http://www.iucnredlist.org/>. Acessado em $05 \mathrm{de}$ outubro de 2009.

Maldonado, S. C. 2002. Botes e tripulação de iguais: Ideário e instrumentos de trabalho na pesca marítima. In: Albuquerque, U. P. A.; Alves, A. G. C.; Silva, A. C. B. L. \& Silva, V. A. (Eds.). Atualidades em etnobiologia e etnoecologia. Sociedade Brasileira de Etnobiologia e Etnoecologia, Recife, Brasil, p.45-56.

Marques, J. G. W. 2002. O olhar (des)multiplicado, o papel do interdisciplinar e do qualitativo na pesquisa etnobiológica e etnoecológica. In: Amorozo, M. C. de M.; Ming, L. C.; Silva, S. $\mathrm{P}$ (Eds.). Métodos de coleta e análise de dados em etnobiologia, etnoecologia e disciplinas correlatas. UNESP/CNPq, São Paulo, Brasil, p.31-46.

Mendonça, J. T. 1998. A pesca na região de Cananéia - SP, nos anos de 1995 e 1996. Dissertação de Mestrado, Universidade Estadual de São Paulo, Brasil, 138pp.

Mendonça, J. T.; Katsuragawa, M. 2001. Caracterização da pesca artesanal no Complexo Estuarino-Lagunar de Cananéia - Iguape, Estado de São Paulo, Brasil (1995-1996). Acta Scientiarum, 23 (2): 535-547.

Meylan, A. B.; Meylan, P. A. 2000. Introducion, historias de vida y biologia de las tortugas marinas. In: Eckert, K. L.; Bjorndal, K. A.; Abreu-Grobois, F. A. \& Donnelly, M. (Eds.). Tecnicas de investigación y manejo para la conservación de las tortugas marinas. Consolidated Graphic Communications, Pennsylvania, USA, p.3-5.

Miller, J. D. 1997. Reproducion in sea turtles. In: Lutz, P. J. \& Musick, J. A. (Eds.). The biology of sea turtles. CRC Press, New York, USA, p.51-81.

Occhipinti, A. G. 1963. Climatologia dinâmica do litoral sul brasileiro: Contribuições do Instituto Oceanográfico. Oceanografia Física, 3: 1-86.

Oliveira, F. C. 2007. Etnobotância da exploração de espécies vegetais para a confecção do cerco-fixo na região do Parque Estadual da Ilha do Cardoso, SP. Dissertação de Mestrado, Universidade Federal de Santa Catarina, Brasil, 146pp.

Pupo, M. M.; Soto, J. M.; Hanazaki, N. 2006. Captura incidental de tartarugas marinhas na pesca artesanal da Ilha de Santa Catarina, SC. Biotemas, 19 (4): 63-72.

Silvano, R. 2004. Pesca artesanal e etnoictiologia. In: Begossi, A. (Ed.). Ecologia de pescadores da Mata Atlântica e da Amazônia. Editora Hucitec, São Paulo, Brasil, p.187-222.

Viertler, R. B. 2002. Métodos antropológicos como ferramenta para estudos em etnobiologia e etnoecologia. In: Amorozo, M. C. de M.; Ming, L. C. \& Silva, S. P. (Eds.). Métodos de coleta e análise de dados em etnobiologia, etnoecologia e disciplinas correlatas. UNESP/CNPq, São Paulo, Brasil, p.11-30.

Wetherall, J. A.; Balazs, G. H.; Tokunaga, R. A.; Young, M. Y. Y. 1993. Bycatches of marine turtles in North Pacific high-seas driftnet fisheries and impacts on the stocks. International North Pacific Fisheries Commission Bulletin, 53 (3): 519-538. 